\title{
HOME MEASURES OF ANXIETY, AVOIDANT COPING AND DEFENCE AS PREDICTORS OF ANXIETY, HEART RATE AND SKIN CONDUCTANCE LEVEL JUST BEFORE INVASIVE CARDIOVASCULAR PROCEDURES
}

\author{
Mieke DE Jong, ${ }^{*}$ Rudolph A. M. ERdman, ${ }^{*} \dagger$ MARCEl J. B. M. VAN DEN BRAND, $\dagger$ \\ Frans Verhage, Rutger W. Trijsburg* and Jan Passchier*
}

(Received 20 April 1993; accepted in revised form 2 November 1993)

\begin{abstract}
The question was whether anxiety, heart rate and skin conductance level just before invasive cardiac procedures could be predicted by anxiety related measures obtained at patients homes approximately 3 weeks before treatment. Trait measures of avoidant coping and defence were provided by sixty-three male and thirty-three female patients who were scheduled for a diagnostic or interventional heart catheterization. In hospital physiological measures were registered continuously during a 20 min interview and subsequently patients reported their anxiety. Results with hierarchical regression analysis showed that sex, age, medical variables and state anxiety at home explained $62 \%$ of state anxiety in hospital. Female sex predicted high anxiety in hospital while advanced age predicted low anxiety. Medical variables and measures of coping and defence did not add a significant contribution to this prediction of anxiety. Skin conductance and heart rate measures could not be predicted by the psychological measurcs collccted at home.
\end{abstract}

\section{INTRODUCTION}

WhILE it is clear that many medical, in particular invasive, treatments are stressful, differences in anxiety about the medical intervention are often unrelated to diagnosis and severity of the physical condition of patients. This suggests the influence of subjective emotional appraisal [1-3]. Anxiety before general surgery has been shown to be an inconsistent but suggestive predictor of outcome measures such as length of hospital stay, return to daily activities and pain medication $[2,4,5]$. The aim of the present study was to predict state anxiety just before treatment from measures of both state and trait anxiety, registered at home in the weeks before treatment. In this study 'home' anxiety was measured approximately 3 weeks before treatment in patients who were scheduled for cardiac catheterization. Trait measures of avoidant coping and defence mechanism 'repression' were included in the predictions. Avoidant coping is characterized by a conscious tendency to distract from a stressor and/or one's reactions to it $[1,6,7]$. Defence has been distinguished as an unconscious mechanism of stress coping [8].

Psychophysiological measures have often been studied for providing links between anxiety and health, mainly in laboratory situations [9]. It has been suggested that extreme stressful circumstances evoke physiological, often sympathetic, activity accompanied with increased behavioural activity and subjective reports of tension,

\footnotetext{
*Department of Medical Psychology and Psychotherapy, Erasmus University, Rotterdam, The Netherlands.

†University Hospital Dijkzigt, Cardiology Department, Rotterdam, The Netherlands.

Address correspondence to: Rudolph A. M. Erdman, Department of Medical Psychology and Psychotherapy, Erasmus University, P.O. Box 1738, 3000 DR Rotterdam, The Netherlands.
} 
TABLE I. - MEDiCAl VARIABLES: TyPE OF TREATMENT AND CARDiaC HISTORY, $N=96$

\begin{tabular}{llll}
\hline Type of treatment & Total & Men & Women \\
\hline Diagnostic catheterization & 47 & 32 & 15 \\
First diagnostic catheterization & $34(72 \%)$ & $23(72 \%)$ & $11(73 \%)$ \\
Interventional catheterization & 49 & 31 & 18 \\
First interventional catheterization & $47(96 \%)$ & $31(100 \%)$ & $16(89 \%)$ \\
Cardiac History & & & \\
Congenital or valvular disorder & 15 & 6 & 9 \\
Myocardial infarction & 33 & 26 & 7 \\
Any cardiac surgery & 13 & 8 & 5 \\
Total & 96 & 63 & 33 \\
\hline
\end{tabular}

while less stressful conditions reveal this pattern only in part [10]. Impending medical invasive situations regarding a life-threatening disease, such as the one under investigation, can be considered as very stressful. Since we were also interested in whether the anxiety at home was related to the sympathetic response in anticipation of the hospital procedure, measures of heart rate and skin conductance were also included in this study.

\section{METHOD}

\section{Subjects}

Patients with a cardiac history, aged between 21 and $70 \mathrm{yr}$ and procifiency in the Dutch language were included in the study. Patients scheduled for a first time diagnostic or interventional catheterization were preferred. Between March 1989 and January 1991158 persons who were on the waiting list for a diagnostic or interventional cardiac catheterization were randomly selected. Of the 158 patients approached, twentysix were excluded, mostly because their treatment became urgent. Of the 132 patients available thirty-four refused to participate $(26 \%)$ of whom many found participation emotionally too demanding. Two patients provided insufficient questionnaire data. Finally, a sample of ninety-six patients resulted, sixty-three men $(66 \%)$ and thirty-three women $(34 \%)$. The average age was $59 \mathrm{yr}$ and was similar for both sexes with $18 \%$ of men and $13 \%$ of women under $50 \mathrm{yr}$ of age.

\section{Medical variables}

Three medical variables were controlled for in the predictions: type of treatment; cardiac history; and medication. Type of treatment was either diagnostic or interventional catheterization. The latter usually involved percutaneous transluminal coronary angioplasty (PTCA). Representation of men and women was equal for treatments. Most patients were treated for the first time (Table I).

The variable 'cardiac history' was measured since the severity of the cardiovascular disease might be related to the anxiety of the patients. The following cardiac diagnoses were considered as indicators of a severe disease: valvular or congenital disease, a myocardial infarction or any cardiac surgery. Regarding medication, betablockers are the best documented medication influencing heart rate [11, 12]. Among men $73 \%$ used this medication, among women $68 \%$. Other categories of medications which were used predominantly were also registered: calcium antagonists; nitrates; and anticoagulants.

\section{Procedure}

At the patient's home questionnaires were completed on anxiety, avoidant coping and defence with the first author available for help. The period between the home visit and admittance to hospital was on average 3 weeks. In hospital patients admitted for interventional catheterization were interviewed in the afternoon with treatment taking place the next morning, while patients for diagnostic catheterization were interviewed in the morning just before treatment. Before the interview started and after attachment of the electrodes for physiological registration, people were seated and a few minutes rest followed. Then 
registration started by recording minimally 3 minutes as a base level. The interview, taking about half an hour involved topics such as the patients feelings and worries about the upcoming medical treatment. Finally, a questionnaire on the anxiety present during the interview was completed by the patient.

\section{Questionnaires}

The Dutch version of the State and Trait Anxiety Inventory was used for measuring state (S-ANX) as well as trait anxiety (T-ANX) [13, 14], both at home and on admittance to hospital. Avoidant coping was registered with two scales of the UCL, a Dutch coping list [15] which was designed to tap coping strategies as behavioural personality styles similar to Westbrook's Cope Scale [16]. The scales selected were: 'Avoidance and Waiting', which reflects passive avoidance coping, and 'Seeking Distraction', which reflects active avoidant coping.

For the measurement of defences the shortened version of the Dutch translation of the Defence Mechanism Inventory (DMI) [17] was used in order to measure repression of affect (REP) according to the procedure of June [18]. Standard instructions were given orally.

\section{Physiological registration}

An ambulatory heart rate and galvanic skin response (GSR) monitor was applied [19] which measures heart beat intervals and GSR simultaneously. GSR was measured at intervals of $200 \mathrm{msec}$. Standard silversilver chloride electrodes were used with a diameter of $2 \mathrm{~cm}$. For heart rate one electrode was placed about $10 \mathrm{~cm}$ under the heart at the left lower part of the rib cage, and one under the right sided collarbone [20]. The two electrodes for measuring skin conductance were attached on the middle part of the inside of the second and third finger of the non-dominant hand [21]. The physiological data were processed by a personal computer yielding heart beats per minute and skin conductance in $\mu$ mhos. Intervals smaller than $0.33 \mathrm{sec}$ and larger than $2 \mathrm{sec}$ were neglected at data processing since these might be due to rhythm disturbances, medication or instrumental artefacts. Heart rate and skin conductance were averaged for: (1) the last minute before the start of the interview (baseline); and (2) the interview (stress level). Finally difference scores for baseline and interview levels were calculated. Temperature and air humidity before and after the procedure were registered and averaged. Coffee and smoking were not allowed during this session [20].

\section{Analysis}

Anxiety. First, paired $t$-tests were performed to test for differences between S-ANX and T-ANX measured at home and at admittance to hospital for males and females separately. Second, Pearson product-moment correlations were calculated between the psychological and physiological measures. Next, hierarchical regression analyses were performed to predict S-ANX in hospital. In the first step, the biographical variables sex and age were entered. Sccondly medical variables were cntercd: i.e. cardiac disorder, treatment, and use of betablockers and, respectively, anti-coagulants. Thirdly, S-ANX and TANX registrated at home were entered. In separate analyses avoidant coping (UCL) and defence (DMI) measures were added to these variables as a fourth step.

Heart rate and skin conductance. Skin conductance data were available for eighty-two persons and heart rate data for sixty-three. The distributions of age, sex and medical variables of these samples were similar to those of the original patient sample.

First $t$-tests were performed between the baseline and stress level for both heart rate and skin conductance. Next, hierarchical regression analyses were performed for each of the three measures (base level, stress level and its difference). The same statistical procedure as for the prediction of anxiety was followed. Air humidity and air temperature were not related to the dependent measure, and therefore, not included in the analyses. Betablockers were anyhow included in the analyses because of reported suppression of sympathetic arousal $[11,12,20]$.

\section{RESULTS}

\section{Anxiety, avoidant coping and defence}

Differences betwecn mcan T-ANX and S-ANX for males and females at home and in hospital are illustrated in Fig. 1.

Mean T-ANX did not change significantly $(p=0.09$ for men and $p>0.10$ for women). S-ANX increased significantly in hospital, compared with S-ANX at home $(p<0.01$ for men and $p<0.001$ for women). Women rated themselves consistently 


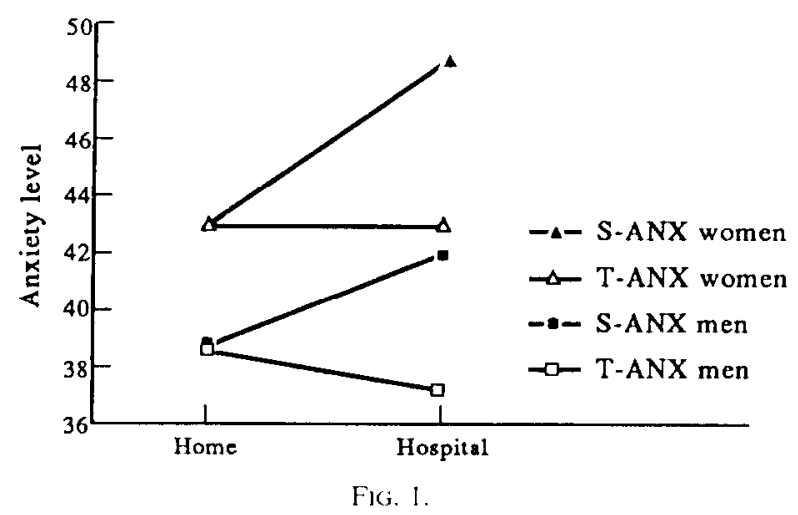

more anxious than men and scored a greater increase in state anxiety in hospital. Table II shows the zero correlations between the psychological and physiological measures. High correlations can be found among the anxiety measures, and in the hospital situation between the anxiety measures and the measures of avoidant coping. The base levels of heart rate and skin conductance were highly correlated with their respective stress levels.

As can be concluded from the table the psychological and physiological measures appear to have very low intercorrelations. Heart rate measures were not correlated with skin conductance. The results of the hierarchical regression analysis on S-ANX in hospital are shown in Table III.

Sex, age, medical variables and anxiety at home predicted $62 \%$ of the variance. Significant predictors were the biographical variables sex and age, explaining $15 \%$ of the variance, and state anxiety at home which explained $45 \%$ of the variance after correction for the other variables. Medical variables, defence and coping measures had no separate significant effects.

\section{Physiological measures}

Results between mean start levels and interview levels of heart rate and skin conductance show no significant differences between men and women. The mean heart rate and skin conductance increased from start level to stress level, respectively from 67.9 to 69.3 and from 10.6 to 15.1 (both $p<0.001$ ). For prediction of heart rates no trends or significance occurred except for the medical variables. For both baseline level and interview level medical variables predicted $9 \%(p=0.02)$ due to the heart rate reduction by betablocking medication. No trends or significance occurred for any of the analyses on skin conductance.

\section{DISCUSSION}

The interview situation at the hospital was clcarly associated with increased emotional stress, as reflected by the increase in state anxiety and the physiological scores. State anxiety at home predicted state anxiety in hospital to a considerable extent. As could be expected trait anxiety remained at the same level on both locations. These findings are in agreement with the original idea that trait anxiety 


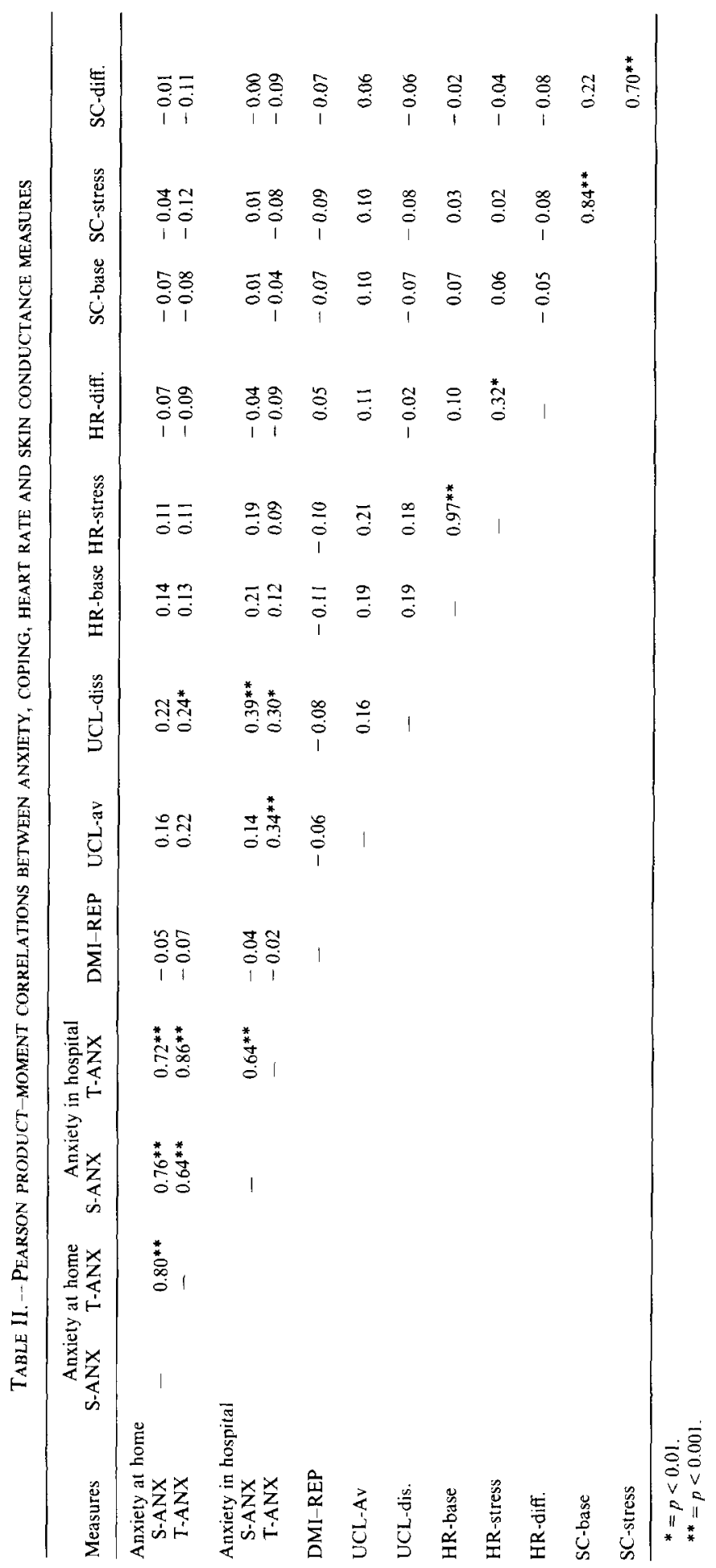




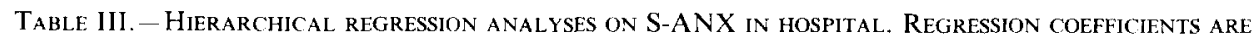
PRFSENTED FOR $R^{2}$ CHANGE WITH $p<0.10$

\begin{tabular}{|c|c|c|c|c|c|c|}
\hline \multicolumn{2}{|c|}{$\begin{array}{l}\text { Predictor } \\
\text { variables }\end{array}$} & \multirow{2}{*}{$\frac{R^{2} \text { adjusted }}{15 \%}$} & \multirow{2}{*}{$\begin{array}{l}\text { Change } \\
\text { in } R^{2}\end{array}$} & \multirow{2}{*}{$\begin{array}{c}\begin{array}{c}\text { F ratio } \\
\text { of Change }\end{array} \\
9.1^{* * *}\end{array}$} & \multirow{2}{*}{$\begin{array}{l}\text { Regression } \\
\text { Coefficient }\end{array}$} & \multirow{2}{*}{$\frac{N}{95}$} \\
\hline 1 & $\begin{array}{c}\text { Biographical } \\
\text { Sex } \\
\text { Age }\end{array}$ & & & & & \\
\hline 2 & $\begin{array}{l}\quad \text { Medical } \\
\text { Betablockers } \\
\text { Anticoagulants } \\
\text { Cardiac history } \\
\text { Treatment }\end{array}$ & $17 \%$ & $2 \%$ & 2.1 & & 95 \\
\hline 3 & $\begin{array}{l}\text { Anxiety } \\
\text { STAI state } \\
\text { STAI trait }\end{array}$ & $62 \%$ & $45 \%$ & $54.8^{* * *}$ & $\begin{array}{l}0.66^{* * * *} \\
0.02\end{array}$ & 95 \\
\hline $4 a$ & $\begin{array}{l}\text { Defence/coping } \\
\text { DMI-rep } \\
\text { UCL avoidance } \\
\text { UCL distraction }\end{array}$ & $64 \%$ & 0 & & & 80 \\
\hline
\end{tabular}

${ }^{*} p<005 ;{ }^{* *} p<0.01 ; * * p<0.001$

reflects a stable characteristic of one's personality which will not change quickly [13, 14]. Surprisingly this study shows that a measure of state anxiety obtained in a relatively peaceful situation can predict more precisely the anxiety of patients in threatening medical circumstances than the trait anxiety.

In the current investigation gender and age were the only other significant predictors: female sex and young age were associated with high anxiety ratings, findings which were found in previous research too [3]. No difference in anxiety measures occurred between people awaiting a diagnostic or interventional catheterization and between those with or without more severe facts in their cardiac history. A similar lack of differences occurred between patients with valvular and coronary disease before heart surgery and between patients with or without myocardial infarction before a first catheterization, which conforms with previous findings [3, 22]. Betablocking medication did not affect anxiety in this study.

The positive correlation between coping by seeking distraction and anxiety in hospital can be explained by the fact that this way of coping with stress is 'blocked' by the interview situation, in which the patient is unavoidably confronted with the anxiety inducing stimulus. Nevertheless, measures of avoidant coping and defence obtained at home could not predict anxiety ratings in hospital. Considering the variance already explained by the anxiety measured at home, this result may be traced by the fact that these mechanisms were not only effective on the anxiety in the hospital but also on that at home. Entering anxiety at home as the first predictor, might have left no variance for coping and defence to explain. However, this explanation is contradicted for avoidance coping and defence by the lack of association between these measures and anxiety at home as shown by Table II.

No relationship between physiological and anxiety measures at home was found. Neither showed a relation between the physiological measures and avoidant coping and defence. As could be expected, the use of betablockers predicted lower heart 
rates, but only to a moderate extent. Few studies in medical situations have shown significant relations between simultaneous self-ratings of anxiety and avoidance coping, and heart rate [1, 23]. In our study, the psychological predictors were collected in a different setting and period from the physiological measures. It is possible that the physiological activity is primarily determined by the present situational psychological and physical conditions. The small response of the heart rate to stress and its low associations with the psychological variables might be explained by the effect of beta blockers on the cardiovascular system.

In conclusion, self-rated state anxiety measured during the waiting period at home predicted state anxiety at admittance to hospital. Preparational intervention programs during the waiting period for a threatening medical intervention might therefore be useful in reducing the patient's feelings of anxiety. Special attention should be paid to females and younger patients because they were found to have high anxiety score just before the medical intervention.

\section{REFERENCES}

1. KaLOUPEK DG, White H, WonG M. Multiple assessment of coping strategies used by volunteer blood donors: implications for preparatory training. J Behav Med 1984; 7: 35-60.

2. Mathews A, Ridgeway V. Personality and surgical recovery: a review. Br J Clin Psychol 1981; 20: 243-260.

3. Schocken DD, Greene AF, Worden TJ, Harrison EE, Spielberger CD. Effects of age and gender on the relationship between anxiety and coronary artery disease. Psychosom Med 1987; 49: 118-126.

4. SimE AM. Relationship of preoperative fear, type of coping, and information received about surgery to recovery from surgery. J Pers Soc Psychol 1976; 34: 716-724.

5. Johnston M, CARPEnTER L. Relationship between pre-operative anxiety and post-operative state. Psychol Med 1980; 10: 361-367.

6. Suls J, Fletcher B. The relative efficacy of avoidant and nonavoidant coping strategies: a metaanalysis. Health Psychol 1985; 4: 249 288.

7. DenOllet J. Negative affectivity and repressive coping:pervasive influence on self-reported mood, health, and coronary-prone behavior. Psychosom Med 1991; 53: 538-556.

8. Freud A. The Ego and the Mechanisms of Defence. New York: International Universities Press, 1966.

9. King AC, Taylor CB, Albright CA. Haskell WL. The relationship between repressive and defensive coping styles and blood pressure responses in healthy, middle-aged men and women. $J$ Psychosom Res 1990; 34: 461-471.

10. PAsschier J. Headache and Stress. Amsterdam: Free University Press. 1985.

11. Prichard BNC. Beta blockade and the effects of stress on the normal and ischaemic heart. Av Space Envir Med 1981; 10: 9-18.

12. Shapiro AP, Krantz DS, Grim CE. Pharmacologic agents as modulators of stress. In Handbook of Stress, Reactivity, and Cardiovascular Disease (Edited by MAtrhews KA. Weiss SM), pp. 406 416. New York: Wiley, 1986.

13. Van der Ploeg HM, Defares PB, Spielberger CD. Handleiding bij de Zelfbeoordelings Vragenlijst, $Z B V$. Een Nederlandstalige bewerking van de Spielberger State-Trait Anxiety Inventory STAI-DY. Lisse:Swets \& Zeitlinger, 1980 (addendum 1981)

14. SpIElberger CD. Test Manual for the State-Trait Anxiety Inventory-STAI form Y. Palo Alto: Consulting Psychologists Press, 1980.

15. Schreurs PJG, Van de Willige G, Tellegen B, Brosschot JF. De Utrechtse Coping Lijst: UCL. Omgaun met problemen en gebeurienissen. Handleiding. Lisse: Swets \& Zeitlinger, 1988.

16. WESTBROOK MT. A classification of coping behavior based on muli-dimensional scaling of similarity ratings. J Clin Psychol 1979; 35: 407-410.

17. Gleser GC, IHLEviCh D. An objective instrument for measuring defence mechanisms. $J$ Cons Clin Psychol 1969; 33: 51-60.

18. JUNI S. The composite measure of the defence mechanism inventory. I Res Pers 1982; 16: 193.200.

19. Barry RJ, Moroney R, Orlebeke JF, De VRies J. HGM I: A research-oriented portable heart rate and galvanic skin response monitor. Int J Psychophys 1991; 11: 61 . 65.

20. Jennings JR, Berg WK, Hutcheson JS, Obrist P, Porges S, Tlrpin G. Committee Report. Publication guidelines for heart rate studies in man. Pswhophysology 1981; 18: 226231. 
21. Fowles DC, Christie MJ, Edelabrg R, Grings WW, Lykken DT, Venables PH. Committee Report. Publication Recommendations for electrodermal measurements. Psychophysiology 1981; 18: 232-239.

22. Magni G, Unger hP, Valfré C, Polesel E, Cesari F, Rizzardo R, Paruzzola P, Gallucci V. Psychosocial outcime one year after heart surgery. Arch Intern Med 1987; 147: 473 477.

23. ShiPley RH, ButT JH, HoRwits B. FARBRY JE. Preparation for a stressful medical procedure: effect of amount of stimulus preexposure and coping style. J Cons Clin Psychol 1978; 46: 499507. 